\title{
Human Immunodeficiency Virus in Semen and Plasma: Investigation of Sexual Transmission Risk Behavioral Correlates
}

\author{
SETH C. KALICHMAN, ${ }^{1}$ MARJORIE CAGE, ${ }^{1}$ TAMARA BARNETT,${ }^{2}$ PHILLIP THARNISH, ${ }^{2}$ \\ DAVID ROMPA, ${ }^{1}$ JAMES AUSTIN, ${ }^{1}$ WEBSTER LUKE, ${ }^{1}$ \\ JULIE O'MOWREY, ${ }^{2}$ and RAYMOND F. SCHINAZI ${ }^{2}$
}

\begin{abstract}
Risks for sexually transmitted HIV may be related to concentrations of virus detected in semen and previous research shows a small to moderate association between viral load in blood and semen. This study examined the association between viral load in semen and plasma in a community sample of HIV-infected men and is the first study to examine semen viral load in relation to sexual transmission risk behaviors. A sample of 44 HIV-positive men recruited from community service agencies provided semen, blood, and urine samples and completed clinical interviews assessing health and behavior. We failed to find an association between viral load in semen and plasma, Spearman $\rho=0.07, p>0.1$. When restricted to participants with detectable virus in semen and plasma, the correlation remained nonsignificant, $\rho=-0.16, p>0.1$. Men who had higher semen viral loads relative to their plasma viral load were distinguished by having engaged in significantly higher rates of unprotected intercourse as the insertive sex partner in the previous 3 months. Semen viral load was not, however, related to recent or current sexually transmitted infections (STIs). This study is among the first to examine sexual transmission risk behaviors as marker for HIV infectiousness. Results caution against inferring sexual transmission infectiousness based on plasma viral load and suggest that HIV-positive men who practice higher rates of insertive intercourse may be more infectious even in the absence of other STIs.
\end{abstract}

\section{INTRODUCTION}

$\mathbf{S}$ TUDIES SHOW that approximately one in three people living with HIV AIDS continues to practice unprotected sexual behaviors, potentially placing themselves and their sex partners at risk for exposure to HIV and other sexually transmitted pathogens. ${ }^{1,2}$ Among the factors associated with continued sexual transmission risk behaviors in HIV-infected people are the perceived benefits of medical advances in HIV treatments. ${ }^{3,4}$ Successful antiretroviral therapy suppresses HIV replication and can reduce the amount of HIV in peripheral blood to levels below detection, suggesting reduced infectivity. Thus, individuals with undetectable virus in peripheral blood may perceive themselves as less infectious and perceptions of reduced infectivity appear to influence sexual transmission risk behaviors in some HIV-infected and uninfected persons. ${ }^{3,5-7}$ There is also evidence that individuals with higher concentrations of plasma
HIV are more likely to transmit the virus to blood recipients, offspring, and sex partners..$^{8-10}$ However, studies that correlate plasma levels of HIV RNA with viral RNA detected in semen demonstrate low to moderate associations; most correlations range between 0.20 and $0.60 .^{9-12}$ In general, plasma concentrations of HIV tend to be higher than concentrations in semen, ${ }^{12,13}$ with HIV RNA as much as 10 -fold higher in plasma than semen. ${ }^{11}$ Accumulating evidence suggests that the male genital tract constitutes a relatively distinct compartment of HIV replication, with long-lived and frequently replicating cells serving as a sanctuary for HIV to replicate protected from immune responses and adequate levels of some antiretroviral therapies. ${ }^{8}$

Explanations of discrepancies between HIV viral loads in plasma and semen have thus far focused on co-occurring ulcerative and nonulcerative sexually transmitted infections (STIs) as factors that promote HIV shedding in the genital tract

${ }^{1}$ Center for AIDS Intervention Research, Medical College of Wisconsin, Milwaukee, Wisconsin 53226.

${ }^{2}$ Emory University School of Medicine and Veterans Affairs Medical Center, Decatur, Georgia 30033. 
and therefore potentially increasing infectivity in people living with HIV AIDS. ${ }^{14}$ In one study, HIV concentrations in semen were 8 times greater in men with clinical urethritis and 10 times greater in men with gonorrhea relative to those without clinical urethritis. ${ }^{15}$ In addition, successful treatments of STIs demonstrate subsequent reductions of HIV in semen, ${ }^{16}$ and treatment of symptomatic STIs can reduce HIV transmission to uninfected sex partners. ${ }^{17}$ Thus, co-occurring STIs appear important in promoting infectivity in HIV-infected men. In addition to infectiousness, HIV transmission is a function of sexual transmission risk practices. Studies have not as of yet, however, investigated behavioral cofactors of infectivity in HIV-infected men.

The current study was conducted to identify behavioral correlates of viral infectivity in HIV-positive men. We were particularly interested in patterns of transmission risk behaviors exhibited by men who were more infectious than implicated by their plasma viral load. Given that greater concentrations of virus are typically detected in plasma relative to serum, ${ }^{12}$ and the demonstrated association between urethritis and viral load in semen, ${ }^{17}$ we hypothesized that men who presented higher viral loads in semen than blood would be more likely to have a recent STI and would exhibit higher rates of HIV transmission risk behaviors than men whose plasma viral load was equal to or less than their semen viral load.

\section{MATERIALS AND METHODS}

Clinical specimens and behavioral data were collected early in the year 2000 and our institutional review board for ethical treatment of human research participants approved the study.

\section{Participants}

We identified $44 \mathrm{HIV}$-infected men from a pool of 242 men participating in a community-based survey to serve as semen and blood donors for this study. Men were originally recruited from infectious disease clinics, AIDS service organizations, and chain recruitment (i.e., word of mouth) to participate in a survey-interview study. After the survey, participants were asked whether they would be willing to take part in a subsequent study that would involve providing semen, blood, and urine samples. Among the 187 (78\%) men who indicated interest in research involving semen collection, we invited 51 randomly selected men to participate in the current study. One participant declined the invitation to participate and six failed to return for specimen collection.

\section{Behavioral assessments}

As part of a larger study and before recruitment for biological specimen collection, participants completed measures of demographic characteristics, health status, and sexual risk behaviors. Therefore, the behavioral assessments were not subject to response biases that can ensue from participating in biological specimen collection. ${ }^{18}$

Demographic characteristics. Participants were asked their age, years of education, ethnicity, relationship status, and whether they identified as homosexual, bisexual, or heterosexual.

Clinical health assessment. To assess current health status, participants reported the year that they first tested HIV positive, whether they had experienced any of 14 symptoms of HIV infection (e.g., persistent respiratory distress, skin rashes, persistent diarrhea, recurring fever, fatigue), had been diagnosed with an AIDS-related condition, and their most recent CD4 ${ }^{+}$ cell count. Participants were also interviewed to determine their antiretroviral therapy history and their 3-day adherence to HIV treatments. ${ }^{19}$ The number of doses missed was summed across medications and was used to calculate a treatment adherence index.

Sexual transmission risk behavior and sexually transmitted infections. Sexual behaviors were assessed by asking participants to report the number of times they had engaged in vaginal intercourse and the number of times they engaged in anal and oral intercourse as the insertive and receptive partner without and with condoms in the previous 3 months. Participants also recorded the number of sexual partners with whom they had engaged in each behavior. Timeframes and dates were used to help cue memory for sexual events and open response formats were used for sexual behavior measures to reduce response bias and to minimize measurement error. Measures similar to these have been found reliable in self-reported sexual behavior assessments. $^{20}$

\section{Biological specimen collection and laboratory analysis}

Participants provided semen, blood, and urine specimens. Immediately after the collection of blood specimens by a certified phlebotomist, participants masturbated into a sterile container to provide semen samples. Blood and semen specimens were transported within $2 \mathrm{hr}$ of collection to a virology laboratory for analysis. Semen samples ranged from $200 \mu 1$ to $1 \mathrm{ml}$ and were aliquoted into $200-\mu \mathrm{l}$ volumes and stored at $-70^{\circ} \mathrm{C}$. Whole blood specimens were centrifuged at $500 \times g$ for $10 \mathrm{~min}$. The plasma was recovered and aliquoted into 200 - to $500-\mu 1$ samples. Initially plasma viral load was determined by Roche (Branchburg, NJ) Amplicor HIV-1 Monitor and by NucliSens HIV-1 QT (Organon Teknika, Boxtel, The Netherlands) with comparable results (data not shown). Both methods are certified for detection of HIV-1 RNA in plasma. Because of the performance in previous research ${ }^{21}$ and our own preliminary analyses that showed the silica method for extraction of viral RNA from semen superior to Roche Amplicor HIV-1 Monitor, NucliSens HIV-1 QT assays were performed to test viral loads in plasma and semen with a detection limit of 100 copies $/ \mathrm{ml}$. Participants were not informed of their viral load test results within this experimental protocol.

During a subsequent appointment, participants provided a urine specimen in a sterile plastic container. Specimens were refrigerated and transported to a microbiology laboratory for processing and analysis by ligase chain reaction (LCR; Abbott Laboratories, Abbott Park, IL) to detect Chlamydia trachomatis (chlamydia) and Neisseria gonorrhoeae (gonorrhea). Participants were notified of positive results and were referred for treatment. 


\section{Statistical analyses}

For the purposes of the current study, groups were defined on the basis of differences between plasma and semen viral loads. Using $\log _{10}$ values for both plasma and semen viral loads, we defined men as either (1) having equal or greater viral loads in plasma relative to semen or (2) having greater values of viral load in their semen relative to plasma. Associations between semen viral load and plasma viral load were examined by using Spearman rank order correlations $(\rho)$. Concordance between undetectable virus in plasma and semen was tested by a contingency table $\chi^{2}$ test and contingency coefficient (CC). Consistent with previous research, ${ }^{11}$ we correlated viral loads for all participants as well as only the subset of participants with detectable virus in their plasma and semen. Group comparisons for continuous measures of demographic and health status characteristics were conducted by $t$ tests and for nominal data we used contingency table $\chi^{2}$ tests. Group differences for sexual practices were tested by analyses of covariance. Because HIV disease processes and sexual practices change over the course of time that a person lives with HIV AIDS, ${ }^{1}$ we controlled the number of years since the participant had tested HIV positive in these analyses. Distributions of sexual behaviors were highly skewed and were transformed for analysis by using the formula $\log _{10}(x+1),{ }^{22}$ with observed values presented in the tables. Significance levels of $p<0.05$ were used for all analyses.

\section{RESULTS}

Among the 242 men who were asked if they would be interested in participating in a study that involved semen collec- tion, 54 declined. Analyses were conducted to identify potential volunteer biases by comparing three groups: (1) men who declined interest in participating $(n=54)$, (2) men who indicated an interest in participating but were not asked to enroll ( $n=138)$, and men who were randomly selected, approached, and enrolled in the study $(n=50)$. Analyses did not indicate any differences in age, years of education, ethnicity, sexual orientation, current relationship status, sexual behaviors, years since testing HIV positive, most recent $\mathrm{CD}^{+}{ }^{+}$cell count, and most recent viral load. We therefore failed to identify potential selection and volunteer biases along key participant characteristics.

\section{Associations between viral load in plasma and semen}

The Spearman's $\rho$ correlation between viral load in semen and plasma was not significant, $\rho(44)=0.07, p>0.1$ (see Fig. $1)$. When restricted to participants with detectable virus in semen and plasma, the correlation remained nonsignificant, $\rho$ (20) $=-0.16, p>0.1$ (see Fig. 2). There was also poor concordance between undetectable viral loads in plasma and semen; $53 \%$ of men with undetectable virus in plasma had detectable viral loads in semen and $31 \%$ of men with undetectable virus in semen had detectable plasma viral loads, $\chi^{2}(1, n=$ $44)=1.0, p>0.1$. The contingency coefficient for undetectable viral load in blood and semen was also nonsignificant, $\mathrm{CC}=0.15, p>0.1$.

\section{Demographic and health status characteristics}

For all participants, the median absolute difference between $\log$ values of viral load in semen and plasma was 0.7 , with greater values in plasma than semen. The greatest difference

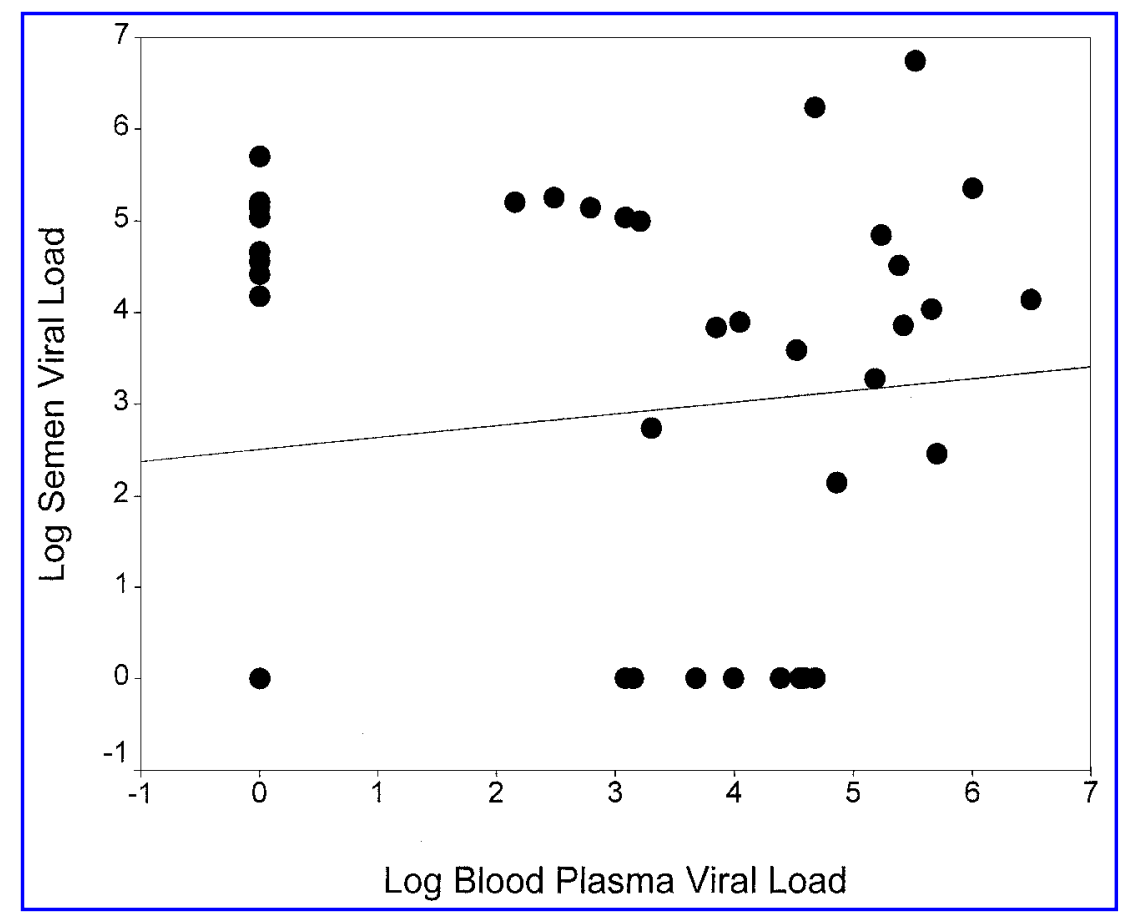

FIG. 1. Scatter plot showing the association of log viral load in semen and log viral load in blood plasma for all study participants. 


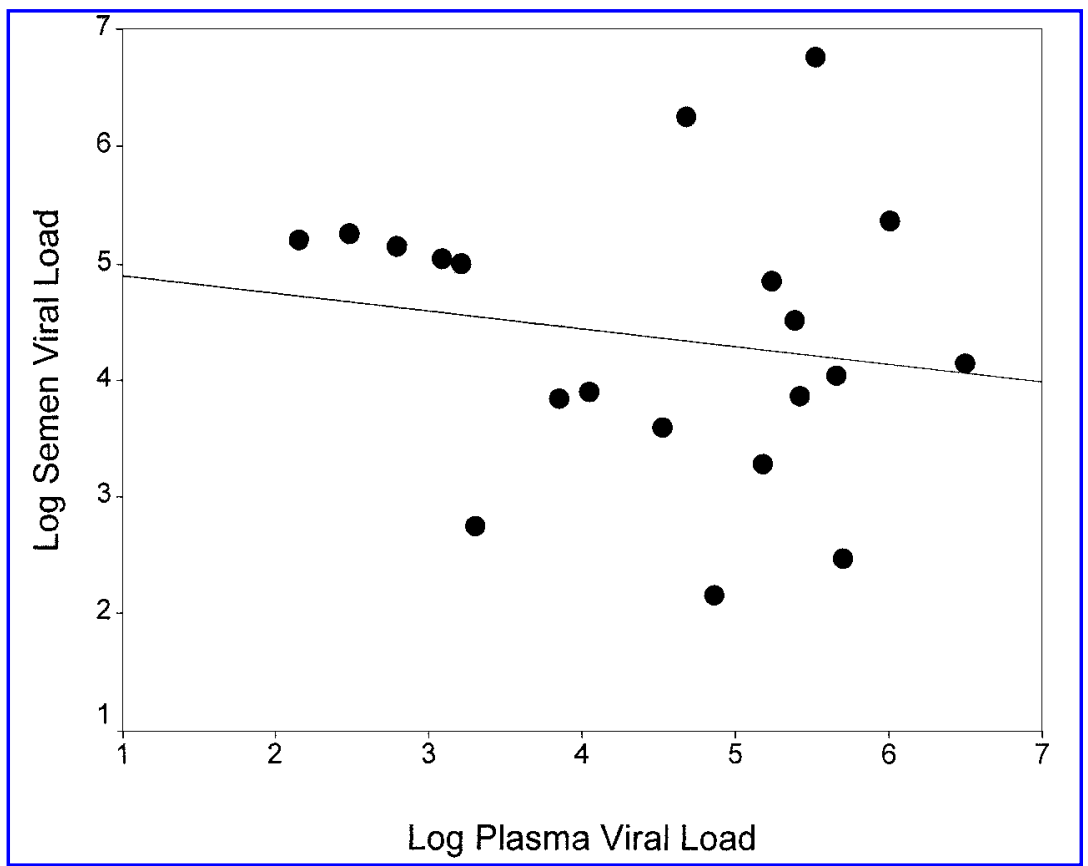

FIG. 2. Scatter plot showing the association of log viral load in semen and log viral load in blood plasma for men with detectable virus in both semen and blood.

between semen and plasma values was 2.7 log copies. A total of $15(34 \%)$ men had greater HIV concentrationsin semen than plasma. Among men with greater viral loads in their plasma than semen, a mean difference of $1.9 \mathrm{log}$ copies of HIV was found in plasma relative to semen. For men who had greater viral loads in their semen than plasma, the mean difference was $3.5 \log$ copies of HIV in semen relative to plasma.

Table 1 presents the demographic and health status characteristics of men with equal or greater viral loads in their plasma than semen in comparison with men with greater concentrations

Table 1. Demographic Characteristics of Men with Higher Viral Loads in Plasma than Semen Compared with Men with Higher Viral Loads in Semen than Plasma

\begin{tabular}{|c|c|c|c|c|c|c|}
\hline & \multicolumn{2}{|c|}{$\begin{array}{l}\text { Higher or equal } \\
\text { HIV concentrations } \\
\text { in plasma than semen } \\
(\mathrm{n}=29)\end{array}$} & \multicolumn{2}{|c|}{$\begin{array}{c}\text { Higher HIV } \\
\text { concentrations in } \\
\text { semen than plasma } \\
(\mathrm{n}=15)\end{array}$} & \multirow[b]{2}{*}{ t Value } & \multirow[b]{2}{*}{$\mathrm{p}$ Value } \\
\hline & Mean & $S D$ & Mean & $S D$ & & \\
\hline Age (years) & 39.7 & 7.0 & 42.3 & 8.2 & 1.2 & NS \\
\hline Years of education & 13.2 & 2.0 & 12.8 & 2.1 & 0.6 & NS \\
\hline Years since tested HIV seropositive & 7.2 & 5.1 & 9.2 & 5.4 & 1.2 & NS \\
\hline Number of current HIV symptoms & 5.0 & 4.3 & 6.2 & 2.5 & 1.0 & NS \\
\hline $\mathrm{CD}^{+}{ }^{+}$cell count $\left(\right.$cells $\left./ \mathrm{mm}^{3}\right)$ & 307.2 & 302.2 & 293.1 & 125.4 & 0.7 & NS \\
\hline Log plasma viral load & 3.5 & 2.2 & 1.6 & 1.9 & 2.8 & $<0.01$ \\
\hline Log semen viral load & 1.7 & 2.0 & 5.2 & 0.7 & 6.6 & $<0.01$ \\
\hline \multirow{2}{*}{$\begin{array}{l}\text { Number of missed medication } \\
\text { doses in past } 2 \text { days }\end{array}$} & 1.0 & 3.0 & 2.9 & 6.1 & 1.1 & NS \\
\hline & $\mathrm{n}$ & $\%$ & $\mathrm{n}$ & $\%$ & $\chi^{2}$ & p Value \\
\hline \multicolumn{7}{|l|}{ Ethnic background } \\
\hline White & 5 & 17 & 4 & 27 & & \\
\hline Minorities & 24 & 83 & 11 & 73 & 0.5 & $\mathrm{NS}^{\mathrm{a}}$ \\
\hline Homosexual/bisexual & 24 & 82 & 10 & 67 & 1.4 & NS \\
\hline AIDS diagnosis & 18 & 78 & 10 & 77 & 0.1 & NS \\
\hline Currently receiving antiretrovirals & 23 & 79 & 12 & 80 & 0.1 & NS \\
\hline
\end{tabular}

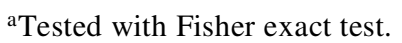




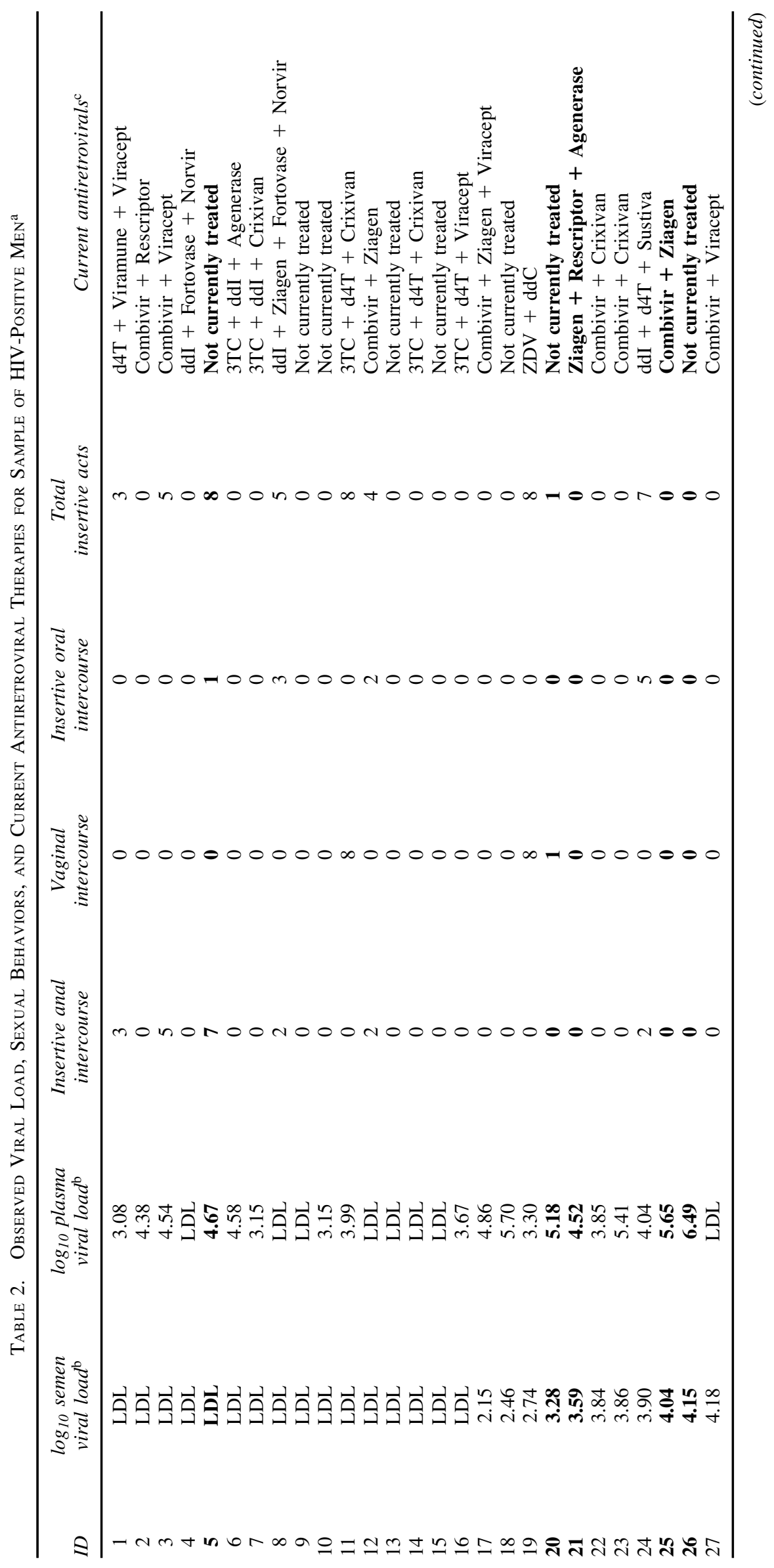




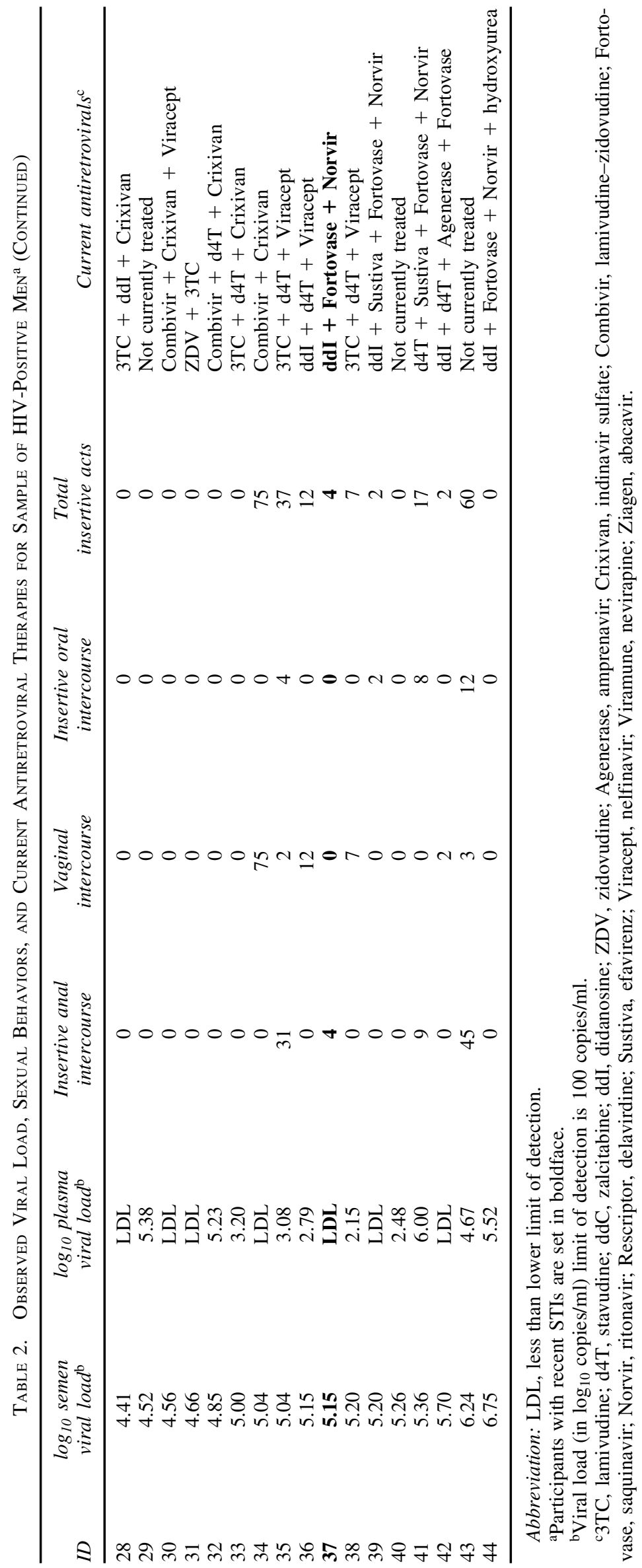


Table 3. Sexual Transmission Risk Behaviors Among Men with Higher Viral loads in Plasma than Semen Compared with Men with Higher Viral Loads in Semen than Plasma

\begin{tabular}{|c|c|c|c|c|c|c|}
\hline \multirow[b]{2}{*}{ Sexual behavior } & \multicolumn{2}{|c|}{$\begin{array}{l}\text { Higher or equal } \\
\text { HIV concentrations } \\
\text { in plasma than semen } \\
(\mathrm{n}=29)\end{array}$} & \multicolumn{2}{|c|}{$\begin{array}{c}\text { Higher HIV } \\
\text { concentrations in } \\
\text { semen than plasma } \\
(\mathrm{n}=15)\end{array}$} & \multirow[b]{2}{*}{$\mathrm{F}(1,41)^{\mathrm{a}}$} & \multirow[b]{2}{*}{$\mathrm{p}$ Value } \\
\hline & Mean & $S D$ & Mean & $S D$ & & \\
\hline Unprotected anal-receptive & 1.0 & 2.3 & 0.2 & 0.4 & 0.8 & NS \\
\hline Unprotected anal-insertive & 0.5 & 1.2 & 3.7 & 10.9 & 0.5 & NS \\
\hline Total unprotected anal intercourse & 1.5 & 2.9 & 3.9 & 10.8 & 0.1 & NS \\
\hline Unprotected vaginal intercourse & 0.1 & 0.7 & 0.7 & 1.4 & 3.9 & 0.05 \\
\hline $\begin{array}{l}\text { Total unprotected insertive anal } \\
\text { and vaginal intercourse acts }\end{array}$ & 2.7 & 4.0 & 13.3 & 24.1 & 4.7 & 0.05 \\
\hline Unprotected oral-insertive & 0.6 & 1.8 & 1.2 & 3.1 & 0.2 & NS \\
\hline $\begin{array}{l}\text { Number of HIV-negative and } \\
\text { unknown HIV status partners }\end{array}$ & 1.9 & 2.7 & 1.5 & 2.1 & 0.1 & NS \\
\hline Total number of partners & 1.9 & 2.3 & 2.7 & 2.7 & 1.6 & NS \\
\hline $\begin{array}{l}\text { Recent diagnosis of a sexually } \\
\text { transmitted infection }(n, \%)\end{array}$ & 4 & 13 & 1 & 7 & 0.5 & NS \\
\hline Diagnosis of a current STD $(n, \%)$ & 1 & 1 & 0 & 0 & & \\
\hline
\end{tabular}

${ }^{\mathrm{a}} \mathrm{F}$ ratios for analyses of covariance adjusted for years since testing HIV positive.

of HIV in their semen than plasma. Men with equal or greater virus in their plasma than their semen compared with men with greater virus in their semen than plasma showed no differences in age, ethnicity, sexual orientation, years since testing HIV positive, HIV symptoms experienced, $\mathrm{CD}^{+}{ }^{+}$cell counts, current HIV treatment status, or current HIV treatment adherence.

\section{Sexual practices and sexually transmitted infections}

Table 2 presents the individual participant log values for viral load in plasma and semen, sorted in ascending order of viral load values in semen, as well as frequencies of insertive sexual intercourse and current antiretroviral regimens. Of 44 men in the study, 16 had semen viral load lower than the level of detection and 15 had undetectable virus in their plasma; among men with detectable viral loads, 7 had both undetectable viral loads in semen and plasma. We grouped together the $15(34 \%)$ men who had viral loads in semen that were higher than viral loads in plasma. Analyses of sexual transmission risk behaviors showed that men with greater concentrations of HIV in their semen relative to concentrations of HIV in plasma reported significantly greater rates of unprotected vaginal intercourse and total number of unprotected sexual intercourse occasions as the insertive partner than men with equal to or greater concentrations of virus in their plasma than semen. The difference for unprotected insertive anal intercourse approached significance $(p<0.06)$. Differences between groups for receptive intercourse acts and numbers of sex partners were not significant (see Table 3).

As shown in boldface in Table 2, five participants had been diagnosed with a sexually transmitted infection in the previous 3 months (participants 5, 21, 25, 26, and 37) and one participant was diagnosed with chlamydia via urine specimens (participant 20). Results failed to find differences in STI occurrences between men with relatively higher and lower semen viral loads.

\section{DISCUSSION}

In contrast to previous research reporting moderate degrees of association between HIV concentrations in plasma and semen, the current study found no such relationship. We also found poor concordance between undetectable levels of HIV RNA in plasma and semen. A factor that may account for these discrepancies is differences in samples under study. Unlike previous investigations of HIV levels detected in semen, the current sample was not solely recruited from infectious disease clinics; one in five of our participants were not currently receiving antiretroviral medications. In addition, our participants who were receiving treatment represented a wide range of antiretroviral regimens, with potential differences among drugs in their penetration of semen. ${ }^{23}$ Therefore, our data suggest that degrees of sexual infectivity in a heterogeneous sample of HIVinfected men cannot be estimated from plasma viral loads. We found that $34 \%$ of HIV-infected men had greater concentrations of HIV in their semen than their plasma-the inverse of the expected direction of association, and a proportion that is similar to the $38 \%$ of men with greater semen than plasma viral loads reported by Tachet et al. ${ }^{12}$ Therefore, a considerable number of HIV-infected men are more infectious than they may assume on the basis of results of viral load assayed from peripheral blood. Although the threshold for HIV infectivity is not yet established and persons with viral loads below levels of detection are likely infectious, studies show that HIV-positive and HIVnegative persons perceive less risk for contracting HIV when HIV-infected persons have undetectable plasma viral loads. ${ }^{3,6,7}$ Transmission risk perceptions may therefore be particularly hazardous because of the inability to infer sexual infectivity from plasma viral loads.

The lack of association between viral load in plasma and semen in the current study could not be accounted for by HIV disease status, antiretroviral therapy history, or current treatment adherence. Some antiretrovirals do not penetrate semen 
as effectively as they do blood, allowing semen to harbor replication-competent virus that can be sexually transmitted. ${ }^{13,23,24}$ We found that $53 \%$ of men with undetectable plasma viral loads had measurable virus in their semen. In addition, the majority of HIV transmission risk behavior in our sample occurred among men who had the highest concentration of HIV in their semen. It is noteworthy that differences in sexual activity between men with higher and relatively lower concentrations of HIV in semen were significant only for insertive sexual acts. One factor that may explain these findings was the potential co-occurrence of other STIs. However, we failed to identify current Gonorrhea, Chlamydia, or clinically reported recent STIs in greater proportions among men with higher viral loads in their semen than plasma. However, our ability to detect associations between semen viral load and STIs was limited by our relatively small sample size. The association of higher rates of insertive intercourse and semen viral loads may therefore be a function of asymptomatic or subclinical urethritis. We are not aware of research that has tested for subclinical urethritis in relation to HIV viral load in semen. We recommend that future research investigating relationships between sexual transmission risk behavior and semen viral loads perform more comprehensive clinical examinations for clinical and subclinical urethritis and conduct more comprehensive testing for STIs on larger samples. We also recommend that HIV-positive men be warned that they cannot infer their infectiousness from their plasma viral load test results and that behavioral risk reduction practices remain the only means for preventing the spread of HIV.

\section{ACKNOWLEDGMENTS}

The authors thank the staffs of the AIDS Survival Project and Mercy Mobile Health Care of Atlanta for their assistance with data collection and Willo Pequegnat for help in planning the study. Supplemental funds from National Institute of Mental Health (NIMH) grant R01-MH57624, Center grant P30 MH52776, the Georgia VA Research Center for AIDS and HIV Infections, the Emory University Center for AIDS Research, and the Department of Veterans Affairs supported this research.

\section{REFERENCES}

1. Kalichman S: HIV transmission risk behaviors of men and women living with HIV-AIDS: Prevalence, predictors, and emerging clinical interventions. Clin Psychol Res Pract 2000;7:32-47.

2. Marks G, Burris S, Peterman TA: Reducing sexual transmission of HIV from those who know they are infected: The need for personal and collective responsibility. AIDS 1999;13:297-306.

3. Kelly J, Hoffman RG, Rompa D, and Gray M: Protease inhibitor combination therapies and perceptions of gay men regarding AIDS severity and the need to maintain safer sex. AIDS 1998;12:F91F95.

4. Miller M, Meyer L, Boufassa F, Persoz A, Sarr A, Robain M, and Spira A: Sexual behavior changes and protease inhibitor therapy. AIDS 2000;14:F33-F39.

5. Van der Straten A, Comez A, Saul J, Quan J, and Padian N: Sexual risk behaviors among heterosexual HIV serodiscordant couples in the era of post-exposure prevention and viral suppressive therapy. AIDS 2000;14:F47-F54.

6. Kalichman SC, Nachimson D, Cherry C, and Williams E: AIDS treatment advances and behavioral prevention set-backs: Preliminary assessment of reduced threat perceptions. Health Psychol 1998;17:546-550.

7. Vanable P, Ostrow DG, McKirnan DJ, Taywaditep KJ, and Hope BA: Impact of combination therapies on HIV risk perceptions and sexual risk among HIV-positive and HIV-negative gay and bisexual men. Health Psychol 2000;19:134-145.

8. Kashuba ADM, Dyer JR, Kramer LM, Raasch RH, Eron JJ, and Cohen MS: Antiretroviral-drug concentrations in semen: Implications for sexual transmission of human immunodeficiency virus type 1. Antimicrob Agents Chemother 1999;43:1817-1826.

9. Vernazza PL, Eron JJ, Fiscus SA, and Cohen MS: Sexual transmission of HIV: Infectiousness and prevention. AIDS 1999;13: 155-156.

10. Quinn TC, Wawer MJ, Sewankambo N, Serwadda D, Li C, Wabwire-Mangen F, Meehan M, Lutalo T, and Gray R: Viral load and heterosexual transmission of human immunodeficiency virus. $\underline{N}$ Engl J Med 2000;342:921-929.

11. Krieger J: Vasectomy and human immunodeficiency virus type-1 in semen. J Urol 1998;159:820-825.

12. Tachet A, Duliust E, Salmon D, DeAlmeid M, Rivalland S, Finkielsztejn L, Heard Jouannet P, Sicard D, and Rouzioux C: Detection and quantification of HIV-1 in semen: Identification of a subpopulation of men at high potential risk of viral sexual transmission. AIDS 1999;13:823-831.

13. Zhang H, Dornadula G, Beumont M, Livornese L, VanUitert B, Henning K, and Pomerantz RJ: Human immunodeficiency virus type 1 in the semen of men receiving highly active antiretroviral therapy. N Engl J Med 1998;339:1804-1809.

14. Friedman SR, Wainberg MA, and Ducker E: Therapeutic ethics and communities at risk in the presence of potential mutation to resistant strains to HIV antiviral medications. AIDS 1998;12:20892093.

15. Cohen MS, Hoffman IF, Royce RA, Kazembe P, Dyer JR, Daly C, Celine C, Zimba D, Vernazza PL, Maida M, Fiscus SA, and Eron JJ: Reduction of concentration of HIV-1 in semen after treatment of urethritis: Implications for prevention of sexual transmission of HIV-1. Lancet 1997;349:1868-1873.

16. Atkins MC, Carlin EM, Emery VC, Griffiths PD, and Boag F: Fluctuations of HIV load in semen of HIV positive patients with newly acquired sexually transmitted diseases. Br Med J 1996;313:341342.

17. Fleming DT and Wasserheit JN: From epidemiological synergy to public health policy and practice: The contribution of other sexually transmitted diseases to sexual transmission of HIV infection. Sex Transm Infect 1999;75:3-17.

18. Tourangeau RS, Tom W, Rasinski, and Kenneth A: Motivation to report sensitive behaviors on surveys: Evidence from a bogus pipeline experiment. J Appl Soc Psychol 1997;27:209-222.

19. Kalichman SC and Rompa D: Functional health literacy is associated with health status and health-related knowledge in persons living with HIV-AIDS. J AIDS 2000;25;337-344.

20. Kauth M, St. Lawrence JS, and Kelly JA: Reliability of retrospective assessments of sexual HIV risk behavior: A comparison of biweekly, three-month, and twelve-month self-reports. AIDS Educ Prev 1991;3:207-214.

21. Barroso PF, Schechter M, Gupta P, Melo MF, Vieira M, Murta FC, Souza Y, and Harrison LH: Effect of antiretroviral therapy on HIV shedding in semen. Ann Intern Med 2000;133:280-284.

22. Tabachnick BG and Fidell LS: Using Multivariate Statistics. 3rd Ed. Harper Collins, New York, 1996.

23. Eron JJ, Smeaton LM, Fiscus SA, Gulick RM, Currier JS, Lennox 
JL, D’Aquila RT, Rogers MD, Tung R, and Murphy RL: The effects of protease inhibitor therapy on human immunodeficiency virus type 1 levels in semen (AIDS Clinical Trials Group protocol 850). J Infect Dis 2000;181:1622-1628.

24. Vernazza PL, Troiani L, Flepp MJ, Cone RW, Schock J, Roth F, Boggian K, Cohen MS, Fiscus SA, Eron JJ, and the Swiss HIV Cohort Study: Potent antiretroviral treatment of HIV-infection results in suppression of the seminal shedding of HIV. AIDS 2000;14: 117-121.
Address reprint requests to: Seth C. Kalichman Center for AIDS Intervention Research (CAIR) Medical College of Wisconsin 8701 Watertown Plank Road Milwaukee, Wisconsin 53226

E-mail: sethk@mcw.edu 


\section{This article has been cited by:}

1. Seth C. Kalichman, Giorgio Di Berto, Lisa Eaton. 2008. Human Immunodeficiency Virus Viral Load in Blood Plasma and Semen: Review and Implications of Empirical Findings. Sexually Transmitted Diseases 35:1, 55-60. [CrossRef]

2. Seth C. Kalichman, Lisa Eaton, Denise White, Charsey Cherry, Howard Pope, Demetria Cain, Moira O. Kalichman. 2007. Beliefs About Treatments for HIV/AIDS and Sexual Risk Behaviors Among Men Who have Sex with Men, 1997-2006. Journal of Behavioral Medicine 30:6, 497-503. [CrossRef]

3. Lisa A. Eaton, Seth C. Kalichman. 2007. Risk compensation in HIV prevention: Implications for vaccines, microbicides, and other biomedical HIV prevention technologies. Current HIVIAIDS Reports 4:4, 165-172. [CrossRef]

4. Robert H. Remien, Theresa M. Exner, Stephen F. Morin, Anke A. Ehrhardt, Mallory O. Johnson, Jackie Correale, Stephanie Marhefka, Sheri B. Kirshenbaum, Lance S. Weinhardt, Mary Jane Rotheram-Borus, Sheryl L. Catz, Cheryl Gore-Felton, Margaret A. Chesney, Jeffrey Kelly. 2007. Medication Adherence and Sexual Risk Behavior among HIV-Infected Adults: Implications for Transmission of Resistant Virus. AIDS and Behavior 11:5, 663-675. [CrossRef]

5. Seth C. Kalichman, Lisa Eaton, Demetria Cain, Charsey Cherry, Howard Pope, Moira Kalichman. 2006. HIV Treatment Beliefs and Sexual Transmission Risk Behaviors among HIV Positive Men and Women. Journal of Bebavioral Medicine 29:5, 401-410. [CrossRef]

6. Robin J. Shattock, John P. Moore. 2003. Inhibiting sexual transmission of HIV-1 infection. Nature Reviews Microbiology 1:1, 25-34. [CrossRef] 